\title{
Topics In Finance Part VI - Capital Budgeting
}

\author{
Judy Laux, Colorado College, USA
}

\begin{abstract}
This series on the theory of financial management offers insight into the roles of stockholder wealth maximization, the risk-return tradeoff, and agency conflicts as they apply to major topics in finance. The current article investigates capital budgeting. Much literature addresses this topic, with a number of articles challenging mainstream theories, some investigating agency problems, and a few empirically testing the relationships taught in most managerial finance classrooms.
\end{abstract}

Keywords: capital budgeting; agency theory; stockholder wealth maximization; discounted cash flows

\section{INTRODUCTION}

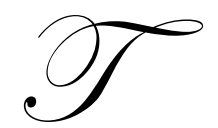

his series is designed to combat the tendency of most current managerial finance textbooks to cover the mechanics of financial management while neglecting the conceptual connections of that nutsand-bolts content to the stockholder wealth maximization, risk and return, and agency constructs; to that end, the series offers brief articles to supplement the introductory finance course. To date, the series has offered an introductory article as well as essays covering financial analysis, leverage, the valuation of stocks and bonds, and capital structure [See Laux 2010 (a), (b), (c), and (d), as well as Laux 2011.]. It is now time to turn to the topic of capital budgeting to address questions such as:

- Why is capital budgeting important?

- What approaches to capital budgeting exist?

- What theories prevail?

- What agency conflicts do financial managers face?

- What aspects of capital budgeting have researchers investigated, and what are their findings?

- What questions should offer direction to the financial manager for making good capital budgeting decisions?

As with past articles, we review the mechanical/conceptual framework commonly presented in textbooks, look at how risk and return and agency problems interface with stockholder wealth maximization, review the literature related to capital budgeting, and conclude by offering advice to the financial manager for tackling the important assignment of implementing the firm's capital budgeting process.

\section{A MECHANICAL AND CONCEPTUAL REFRESHER}

In this series, the returns to investors covered in "Part IV Valuation" were converted to the cost components of the weighted average cost of capital (WACC) of "Part V Capital Structure," and now, at least in theory, financial managers use the (minimized) WACC to judge the acceptability of long-term projects requiring capital investment. The allocation of long-term capital is called capital budgeting, and while accepting or rejecting any single project probably would have little impact on the short-term survival of the firm, these judgments in the aggregate determine stockholder wealth in the long term. This makes the topic crucial to stockholder wealth maximization. 
The most widely employed models include two that would be considered by many to be antiquated (or at least unsophisticated) - the payback period and "urgency and persuasion"-and two that rely on discounted cash flows - internal rate of return and net present value. The payback period considers the number of years of returns required to recover the initial investment (the shorter, the more desirable with a maximum number of years often considered in the accept/reject decision); neither the timing of the cash flows nor the ultimate profitability of the project matters. Proponents of this approach argue that it is simple and addresses risk appropriately for many projects. Urgency (the machine breaks and therefore must be replaced) and persuasion (the most convincing manager, or the one with the greatest power, gets the capital budgeting dollars) do not measure up in an economic sense, because ultimate profitability, timing of cash flows, and other economic variables play no formal role. Still one would be remiss in not mentioning these oft-used approaches. The internal rate of return (IRR) and net present value (NPV) models consider both the timing of cash flows and the ultimate profitability of the project, and thus these discounted cash flow models warrant a bit more description and elaboration.

The IRR model uses the initial outlay and the expected future cash flows to solve for the discount rate that would equate the two, the internal rate of return in present value terms. Acceptability of projects then depends on whether or not that internal rate of return equals or exceeds the "hurdle rate" (typically, the WACC, but more on that later). Projects can be ranked from highest to lowest IRR, with the highest being considered superior. The reinvestment rate assumption constitutes a drawback of this approach, as it assumes that every time a cash inflow occurs it can be reinvested to earn the IRR for the remainder of the project's life. Sometimes this is an unrealistic assumption, especially for high-IRR projects. Thus many contend that the NPV approach is superior, as described below.

In contrast to the IRR model, its close cousin the NPV approach assumes AS the discount rate for future cash flows the hurdle rate (or WACC) in determining the total present value of those future cash flows. From this value the outlay is subtracted to calculate the net present value with the following decision rule: If the NPV is greater than or equal to zero, accept the project. Essentially, if the project's risk aligns with the risk of the firm's assets, a zero NPV would maintain the value of the firm; positive NPV projects would increase firm value. A variant on this model, the NPV index approach would "standardize" projects of different size by dividing the NPV by the outlay required, with projects ranked from highest to lowest based on the size of this index.

Because of their general reliance on estimated future cash flows, each of the models above can be effective only insofar as those projections are accurate. These represent the returns, and financial managers' ability to estimate them constitutes a big part of the risk profile. The following section addresses the relationships among risk, return, agency conflicts, and stockholder wealth maximization.

\section{THEORETICAL CONSTRUCTS AND CAPITAL BUDGETING}

As has been the case with every topic in this series, risk and return, agency costs, and stockholder wealth maximization play critical roles in capital budgeting. Often agents are tempted to amplify expected returns and disguise risk in their attempts to secure a piece of the capital budgeting pie; as expected, this does not always serve to enhance stockholder wealth. This section highlights some of the most problematic elements of these theoretical themes.

In considering the risk aspect of capital budgeting, managers should apply the models outlined in the previous section to projects that lie within the general risk profile of the firm's business. If the risk associated with a project vying for capital investment is greater than normal, the project should be subjected to a quicker payback period or a higher hurdle rate than the WACC for the discounted cash flow approaches. Similarly, if the project is exceptionally routine and perhaps even less risky than the norm, the manager should employ less challenging hurdles. Unfortunately, the risk of projects is quite difficult for external parties to police, as no required disclosure rules apply. This can open the door for agency conflicts, as managers underestimate risk and accept projects that should be rejected.

The return dimension of capital budgeting comes with its own special challenges. Estimating future cash flows, their timing, and the level of their uncertainty comprises the biggest challenge for most managers, yet this 
receives relatively little attention in the textbook setting (or falls in a chapter separated from the capital budgeting models, increasing the likelihood that professors will not devote time to both or the likelihood that students will not quite get to it!). In capital budgeting cash flow analysis, return and risk must be considered jointly, as managers employ techniques such as risk-adjusted discount rates, certainty equivalents, Monte Carlo simulation, and the like to recognize and adjust for the potential misbehavior of cash flows. Corporate income taxes also represent another complicating factor, as they affect cash flows. Tax-related complexities for decisions such as equipment replacement can become involved. After-tax savings, depreciation tax shields, the tax impacts of gains or losses on sale, and intermittent tax credits for new capital purchases all conspire to increase the intricacy of certain capital budgeting investments. Perhaps the most problematic of all, however, are the personal and behavioral aspects of long-term capital allocations.

Among the people-related complexities and items typically carrying agency costs are the following, each of which will be treated in turn:

- $\quad$ Finding the personnel required for all acceptable projects

- Weighing the costs and benefits of centralization versus decentralization

- $\quad$ Creating the self-discipline to perform post-audits

- $\quad$ Recognizing sunk costs

- Including all real economic costs (cannibalization of similar product lines, pollution and other externalities)

- $\quad$ Recognizing (and controlling) information asymmetry

- $\quad$ Resisting the temptation to build empires

- $\quad$ Controlling free cash flow

Managers often can find a number of acceptable projects and secure funding for them but cannot launch them due to constraints associated with personnel. Projects require managerial expertise and time to oversee them; sometimes the projects outnumber the available managers. This can result in theoretically indefensible capital rationing. New managers should be hired to carry out the projects, surmounting this constraint. In reality, projects often are rejected despite the fact that the benefits of the related growth would accrue to the stockholders.

Capital budgeting can occur in a centralized setting in which top management controls the allocation of investment dollars or in a decentralized setting in which divisional managers vie against one another for capital project funding. While the former alleviates agency costs, it also results in less commitment from divisional managers than the approach in which they become responsible for finding and approving specific projects. The challenge is to find the appropriate balance between the benefits of decentralization (responsiveness to customers, suppliers, and employees, faster decision making, increased motivation, etc.) and the potential costs of such independence (suboptimal decision making, focus on the subunit, duplication of output and activities, etc.) [Horngren, 2012, pp. 777-78].

Textbooks often comment that firms do a better job of finding, funding, and running projects than they do in judging after the fact whether or not the estimates that led to acceptance were realized. This review process is referred to as a "post audit," and (theoretically) it should be used as an instrument to ensure learning over timeaccepting better and better projects and improving future estimates. Post-investment audits help protect against managerial tendencies to promote projects by over-stating potential cash flows. Such audits can also "help alert senior management" to "implementation problems" (weak project management, poor quality control, or inadequate marketing") [Horngren, 2012, p. 756]. Some of the literature indicates that these audits do, in fact, take place [See Klammer, Wilner, and Smolarski, 2002, as cited in Koch, Mayper, and Wilner, 2009, for a report on the extent of this activity.]. Perhaps because no formal cash flow reporting for individual projects is required, those of us external to the firm simply do not see this post audit information. A final weakness of the audit process is the apparent disconnect between the use of discounted cash flow to accept projects and the use of accrual-based accounting, including losses on sale, to judge managerial performance. This tempts managers to make capital budgeting decisions based on (inappropriate) measures. 
Any student who has taken an introductory course in economics is familiar with the term "sunk costs"costs that are irrelevant to decisions because they cannot be changed and will not differ among future alternatives. However, in reality, managers can fixate on a past decision and allow this to interfere with judgments related to capital budgeting. For example, consider the manager who has underestimated demand and purchased a semiautomatic machine that is more costly to run for the production levels that have materialized. Replacing the machine with an automatic counterpart might make good sense (might pass all the discounted cash flow hurdles) but would require recognizing a "Loss on Sale" from the old machine, which would dampen current earnings per share. Though not a "cash flow" and not relevant to the current proposal to purchase a better, faster, more efficient machine, the manager in all likelihood will take actions to avoid the "loss," perhaps even hiding the issue entirely by not proposing a machine purchase at all. This "two-wrongs-does-not-make-a-right" behavior will fail to maximize shareholder wealth, though it may well lead to a better bonus for the manager if bonuses are a function of earnings per share in the division.

Sins of omission can also occur when externalities are not incorporated into capital budgeting decision models. New product lines can excite managers and customers, but if they would transfer demand from existing products (referred to as cannibalization), any resultant cash flow loss must be recognized in the analysis. Because the products might be under the control of different managers, however, "'fessing up" can be hard to do. The more decentralized a company is, the more likely this type of problem is to develop. In a similar vein, managers will concentrate on expected future cash flows only, and this might lead to overlooking the kinds of costs economists refer to as externalities, the often negative consequences (such as pollution) that do not always have cash flow implications. Underestimating the true costs of capital projects does not serve society and might not serve stockholders over the long run if companies develop poor reputations by investing in projects/products that invite reprehension because companies shirk responsibilities deemed important to society just to charge a lower price. As with the machine replacement example cited above, managers have information that they can choose to share or not share, and this information asymmetry plagues the capital budgeting process.

Information asymmetry comes in a number of guises in the capital budgeting arena. The informationgathering process falls to the manager seeking capital project funding, and each manager feels compelled to bring the most favorable projects forward. Thus the temptation exists to maximize the expected cash flows and minimize the perceived riskiness to generate the best profile. "Empire building," or the desire to capture as many of the capital budgeting dollars as possible for your own division, appears to be "hard-wired" in many managers. This can result in investment in projects that only appear to clear the hurdles but, in fact, generate true returns below the required return. A number of articles in the review of literature section that follows address this propensity as well as contractual arrangements, including compensation arrangements, designed to control it.

One way external parties can detect the existence of ill-advised investments is by monitoring free cash flow-the residual remaining after subtracting from operating cash flows the capital investments and payments to those financing them (interest and dividends). Good financial managers will recognize their duty to return excess funds to the stockholders who can invest them in other companies earning suitable returns on their projects. Of course, this requires a tacit admission by the financial managers that they have failed to find such projects, a dilemma for most humans. As this section has suggested, the academic approaches and those of practitioners don't always coincide, and the following section offers coverage of some pertinent capital budgeting literature that underscores that fact.

\section{CAPITAL BUDGETING IN THE LITERATURE}

The capital budgeting literature is vast, but several articles since 2000 give a good idea of how researchers have treated some of the ideas presented in the current paper. This section groups those articles into two categories: Capital budgeting approaches and principal-agent challenges.

\section{Capital Budgeting Models}

While some researchers focus on the cost of capital input into the discounted cash flow (DCF) capital budgeting models, others debate the relative strength of the different models themselves. Because the estimation of 
the cost of capital determines project acceptability in the DCF models, mistaken estimations can cause poor acceptreject decisions. The Capital Asset Pricing Model (CAPM) takes center stage in the literature as one technique for estimating the cost of the equity component of the weighted average cost of capital, but the model has received much criticism over the past decades [See Laux, 2010 (d) and Laux 2011 for coverage of some of this literature.] In "Toward an Implied Cost of Capital," Gebhardt, Lee, and Swaminathan [2001] offer a model to the financial manager for approximating the firm's cost of capital. The authors suggest that a firm's cost of capital "...is a function of its industry membership, $\mathrm{B} / \mathrm{M}$ ratio, forecasted long-term growth rate, and the dispersion in analyst earnings forecasts" (p. 135). Jagannathan and Meier [2002] question whether we even need CAPM for capital budgeting, contending that capital rationing exists to such an extent that misestimates of the WACC based on CAPM don't really matter - most projects actually undertaken have internal rates of return in excess of that measure anyway.

Academics consider the NPV approach superior, and Ryan and Ryan [2002] find that, over time, practitioners have come to agree. However, discounted cash flow models, while considered more sophisticated than those that do not consider the time value of money, still have their detractors. Adler [2006] argues that the assumptions of DCF capital budgeting models are so unlikely to hold in reality that business schools do a disservice by even teaching them. Capital budgeting projects tend to be so complex that data are not available for the most essential parameters required by DCF models. Adler cites the following limitations: “...narrow perspective, exclusion of non-financial benefits, over-emphasis on the short-term, faulty assumptions about the status quo, inconsistent treatment of inflation, and promotion of dysfunctional/cheating behavior" (p. 4). In short, strategy lies at the heart of long-term investment, and strategy involves a level of complexity that cannot be reduced to mere financial numbers. If one desires to cut content in the financial management curriculum, Adler suggests we start by cutting this topic. Two commentaries on this very article, however, recommend that we not throw the baby out with the bathwater. Wouters [2006] and Weil and Oyelere [2006] see value in the framework offered by DCF modeling. Both argue that DCF models should be used in conjunction with other strategic investment decision models. Two other supporters of the NPV approach, Berkovitch and Israel [2004] bemoan the fact that, while this approach could lead to optimal decisions, it is dominated by other models such as IRR and the profitability index. Thus, "while firms use NPV to measure the addition to firm value from prospective projects, 'classical' information and agency considerations prevent it from implementing the optimal capital budgeting outcome" (p. 239).

Perhaps recognizing the deficiencies of models (and their assumptions) is a valuable learning experience in itself. One study promotes the use of the simplistic and unsophisticated payback model on the very basis that certain environments render NPV inappropriate. Boyle and Guthrie [2006] make a pretty good argument:

When interest rates are uncertain, the net-present-value threshold required to justify an irreversible investment is increasing in the length of a project's payback period. Therefore, slow-payback projects should face a higher hurdle than fast-payback projects, just as investment folklore suggests. This result suggests that the widely disparaged use of payback for capital budgeting purposes can be an intuitive response to correctly perceived costs and benefits. (p. 1)

Furthermore, they cite studies indicating that "between 40 and 90 per cent of US firms use payback as a capital budgeting technique over time" (p. 2). Finally, their "model predicts that payback should be used in conjunction with NPV or some other discounted cashflow method..." (p. 7), a stance supported by Arnold and Hatzopoulos [2000] whose study of UK corporations finds a growing propensity to use prescribed textbook financial analysis, not in place of the simpler techniques, but in addition to them. Another empirical study investigates whether capital budgeting procedures differ significantly between industries. Block [2005] finds differences in a number of decision-making areas, including goal setting (it's not always SWM!), rates of return, and portfolio considerations. Capital budgeting is complex, and this forces financial management instructors to focus on relatively few "teaching points." Among these, cash flows and risk-return tradeoffs represent such critical concepts in accounting and finance that one should not pass up the opportunity to present them in yet another context.

This section presenting conceptual and theoretical literature would not be complete without recognizing the contributions of Stewart Myers to the area of capital budgeting. As outlined in Allen, Bhattacharya, and Rajan [2008], among the ground-breaking ideas related to capital budgeting, Myers offered the value additivity concept 
(investments should be treated separately from one another and not in a portfolio context). This represented a meaningful departure from earlier work by Markowitz suggesting that corporate diversification would contribute to higher firm value and shareholder wealth. Allen et al. reflect that, in his work, Myers recognized some of the same deficiencies of the DCF model pointed out by Adler [2006] and Boyle and Guthrie [2006]: "What is missing from simple DCF analysis is the ability to model the flexible responses of corporate managers and other decision-makers when new information becomes available" [Allen et al., p. 16]. This implies that (1) models such as the payback period have some usefulness when used in tandem with DCF, and (2) human intervention as new information surfaces can enhance capital budgeting decisions. This second observation provides the foundation for the following section addressing literature associated with the behavioral aspects of capital budgeting.

\section{Agency Theory In The Capital Budgeting Literature}

While all capital budgeting models discussed above generate a numerical output used to make long-term investment decisions, numbers cannot tell the whole story, because people generate the numbers. This human aspect leads to "gaming" the system in pursuit of control, power, benefits, and other coveted outcomes that can obstruct shareholder wealth maximization. In addition, managers are subject to risk aversion (or risk taking) behaviors that can impede their ability to achieve this assumed goal. The literature offers a look at several of these aspects.

Corporate socialism and the free rider problem represent themes in three articles. In "Green with Envy: Implications for Corporate Investment Decisions," Goel and Thakor [2005] investigate how the utility gained by managers when their consumption exceeds that of their reference group affects investment in centralized versus decentralized capital budgeting systems. Centralized environments can lead to corporate socialism (wherein CEOs award projects to satisfy disgruntled managers), and envy can lead to overinvestment as it "creates a natural propensity for managers to overinvest so as to hoard resources and deny them to others in the organization" [Goel and Thakor, 2005, p. 2260]. Of course, both outcomes reduce firm value. Although authors Scharfstein and Stein [2000] also believe that corporate socialism exists, they explain it differently, and once again the CEO and managers play the role of the primary culprits. The CEO, in an attempt to get the manager to turn away from wasteful rentseeking behavior to more productive work, allocates more non-cash resources than capital budgeting models would dictate - an action not easily tracked by stockholders whose wealth is being reduced. In addition, the greatest inefficiencies occur "when there is a great deal of divergence in the strength of the divisions" (p. 2540). Finally, de Motta [2003] suggests that “...corporate headquarters' informational advantage, while improving the allocation of resources, might have adverse consequences for managerial incentives [because] each division manager takes the external perception of the whole firm as a public good and is tempted to free ride" (p. 1212); with no external eyes evaluating his/her own division, the divisional manager has no incentive to maximize the value of the whole firmothers will do this for him or her. Thus, the centralize-versus-decentralize choice assumes some importance. So, too, does information asymmetry, as external investors lack access to divisional profitability and therefore cannot judge managerial efficiency at that level.

Two articles hone in on the issue of decentralization. Baldenius [2003] argues that decentralization promotes empire building, a negative activity that can be offset by applying a higher required rate of return for capital budgeting projects. In short, "...the hurdle rate is always higher under delegation than under centralization" [Baldenius, 2003, p. 911, italics deleted]. Thus, the author makes a case for alternative forms of hurdle rates. Marino and Matsusaka [2005] find that both centralized and decentralized schemes have their drawbacks. "Processes that delegate aspects of the decision to the agent [decentralization] result in too many projects being approved, while processes in which the principal retains the right to reject projects [centralization] cause the agent to strategically distort his information about project quality" (p. 301); the latter results in "an inefficiently large capital allocation" as well (p. 320).

Finally, emotions provide the focus of a number of articles investigating capital budgeting behavior. In "The Impact of Affective Reactions on Risky Decision Making in Accounting Contexts" [2002], Moreno, Kida, and Smith contend that emotions, even when based on data, counteract (and can even overcome) classical prospect theory, which says that decision makers tend to be risk averse in settings with potential gains but risk taking in loss settings. This "normal" setting only applies in the absence of other decision-relevant characteristics. Because managers are human and are "likely to reject decision alternatives that elicit negative reactions and accept 
alternatives that elicit positive reactions" (p. 1333), their affective reactions (evaluations, moods, and emotions) can "negate prospect theory's predictions, resulting in risk taking in gain contexts and risk aversion in loss contexts" (p. 1336), sometimes resulting in the choice of alternatives with lower economic value.

Risk-taking/risk-avoidance also relates to a manager's job security and compensation. Bernardo, Cai, and Luo [2004] focus on the compensation mechanism that best promotes truthfulness in information that managers provide in capital requests. They suggest that "compensation schemes such as shares in the firm...or stock options... are likely to provide powerful incentives for managers to report truthfully their private information and allocate efficiently the resources under their control" (p. 758). Dutta [2003] investigates the problem of managerial mobility and suggests that the owner can counteract the manager's urge to go elsewhere by reducing the hurdle rate required to approve investment projects for these mobile managers. "Green with Envy..." (cited above) also highlights some findings related to compensation: “...the average compensation of managers in a conglomerate exceeds the average compensation of similar managers in single-segment firms [and] the cross-sectional variation in wages among managers in a conglomerate is less than that across managers in separate single-segment firms; that is, there is wage compression in conglomerates" (p. 2261). The implication is that envy raises its ugly head in a more pronounced fashion in the conglomerate environment, and perhaps because it is harder to monitor individual performance in that environment, all managers partake (in roughly even manner) in the higher wages. The bottom line, of course, is that all of this imperils stockholder wealth maximization in the capital budgeting arena.

This literature review charts a difficult course for the financial manager with respect to capital budgeting activities. How can managers combat the uncertainties and human frailties associated with this important activity?

What advice can we offer financial managers who find themselves on the journey? The next section outlines some potentially enlightening questions.

\section{THE BOTTOM LINE: CAPITAL BUDGETING ADVICE FOR THE FINANCIAL MANAGER}

In navigating their way through the choppy seas of capital budgeting, financial managers might benefit by employing the following questions (and suitable answers) to help them set the compass:

- $\quad$ Have we fairly estimated the cash flow projections used in our capital budgeting models? (Yes)

- Have we refused to boost EPS (and associated bonuses) with profitable projects returning less than the weighted average cost of capital? (Yes)

- Is the risk of our capital projects in line with that of our firm as a whole, or if not, have we adjusted the discount rate accordingly? (Yes)

- $\quad$ Does the "urgency and persuasion" model determine capital allocation in our firm? (No)

- $\quad$ Are we guilty of capital rationing, failing to accept and fund all projects returning the WACC or above? (No)

- Has limited access to capital markets interfered with good capital budgeting decisions? (No)

- Have we considered our dividend policy in tandem with our capital budgeting decisions? (Yes)

If the financial manager can answer these questions honestly and let the answers drive proper action, the stockholders' chances for maximized long-run wealth should be enhanced.

\section{THIS SERIES CONTINUES}

This article has raised some hard questions about the capital budgeting assignment. In fact, capital budgeting has implications for another major assignment, dividend policy, because whatever is not invested in longterm projects will be retained or paid out as dividends. Thus, dividend policy naturally assumes its rightful position as the next topic in this series. 


\section{AUTHOR INFORMATION}

Judy Laux is a Gerald L. Schlessman Professor of Economics and Business at Colorado College, teaching and researching in the areas of accounting and finance. The author wishes to thank the Chapman Foundation for funding support for the current series.

\section{REFERENCES}

1. Adler, Ralph W. 2006. Why DCF Capital Budgeting is Bad for Business and Why Business Schools Should Stop Teaching it. Accounting Education: An International Journal, Vol. 15, No. 1: 3-10.

2. Allen, Franklin, Sudipto Bhattacharya, and Raghuram Rajan. 2008. The Contributions of Stewart Myers to the Theory and Practice of Corporate Finance. Journal of Applied Corporate Finance, Vol. 20, No. 4: 819.

3. Arnold, Glen C. and Panos D. Hatzopoulos. 2000. The Theory-Practice Gap in Capital Budgeting: Evidence from the United Kingdom. Journal of Business Finance \& Accounting, Vol. 27, Nos. 5 and 6: 603-626.

4. Baldenius, Tim. 2003. Delegated Investment Decisions and Private Benefits of Control. The Accounting Review, Vol. 78, No. 4: 909-930.

5. Berkovitch, Elazar and Ronen Israel. 2004. Why the NPV Criterion does not Maximize NPV. Review of Financial Studies, Vol. 17, No. 1: 239-255.

6. Bernardo, Antonio E., Hongbin Cai, and Jiang Luo. 2004. Capital Budgeting in Multidivision Firms: Information, Agency, and Incentives. Review of Financial Studies, Vol. 17, Issue 3: 739-767.

7. Block, Stanley. 2005. Are There Differences in Capital Budgeting Procedures Between Industries? An Empirical Study. Engineering Economist, Vol. 50, Issue 1: 55-67.

8. Boyle, Glenn and Graeme Guthrie. 2006. Payback without apology. Accounting and Finance, Vol. 46: 110.

9. De Motta, Adolfo. 2003. Managerial Incentives and Internal Capital Markets. The Journal of Finance, Vol. LVIII, No. 3: 1193-1219.

10. Dutta, Sunil. 2003. Capital Budgeting and Managerial Compensation: Incentives and Retention Effects. Accounting Review, Vol. 78, Issue 1: 71-93.

11. Gebhardt, William R., Charles M. C. Lee, and Bhaskaran Swaminathan. 2001. Toward an Implied Cost of Capital. Journal of Accounting Research, Vol. 39, No. 1: 135-176.

12. Goel, Anand and Anjan V. Thakor. 2005. Green with Envy: Implications for Corporate Investment Distortions. Journal of Business, Vol. 78, No. 6: 2255-2287.

13. Horngren, Charles T., Srikant M. Datar, and Madhav V. Rajan. 2012. Cost Accounting: A Managerial Emphasis (Upper Saddle River, NJ: Pearson Prentice Hall).

14. Jagannathan, Ravi and Iwan Meier. 2002. Do We Need CAPM for Capital Budgeting? Financial Management, Winter: 55-77.

15. Klammer, T., N. Wilner, and J. Smolarski. 2002. A Comparative Survey of Capital Budgeting Practices in The United States and The United Kingdom. International Business and Economic Research Journal: 103114.

16. Koch, Bruce S., Alan G. Mayper, and Neil A. Wilner. 2009. The Interaction of Accountability and PostCompletion Audits on Capital Budgeting Decisions. Academy of Accounting and Financial Studies Journal, Vol. 13, Special Issue: 1-26.

17. Laux, Judith A. 2010. Topics in Finance: Part I-Introduction and Stockholder Wealth Maximization. American Journal of Business Education, Vol. 3, No. 2: 15-21.

18. 2010. Topics in Finance: Part II—Financial Analysis. American Journal of Business Education, Vol. 3, No. 3: 81-88.

19. 2010. Topics in Finance: Part III-Leverage. American Journal of Business Education, Vol. 3, No. 4: 13-18.

20. 2010. Topics in Finance: Part IV—Valuation. American Journal of Business Education, Vol. 3, No. 9: 16.

21. 2011. Topics in Finance: Part V—Capital Structure. American Journal of Business Education, Vol. 1, No. 1: 79-87. 
22. Marino, Anthony M. and John G. Matsusaka. 2005. Decision Processes, Agency Problems, and Information: An Economic Analysis of Capital Budgeting Procedures. The Review of Financial Studies, Vol. 18, No. 1: 301-325.

23. Moreno, Kimberly, Thomas Kida, and James F. Smith. 2002. The Impact of Affective Reactions on Risky Decision Making in Accounting Contexts. Journal of Accounting Research, Vol. 40, No. 5: 1331-1349.

24. Ryan, Patricia A. and Glenn P. Ryan. 2002. Capital Budgeting Practices of the Fortune 1000: How Have Things Changed? Journal of Business \& Management, Vol. 8, Issue 4: 355-364.

25. Scharfstein, David S. and Jeremy C. Stein. 2000. The Dark Side of Internal Capital Markets: Divisional Rent-Seeking and Inefficient Investment. The Journal of Finance, Vol. LV, No. 6: 2537-2564.

26. Weil, Sidney and Peter Oyelere. 2006. A Commentary on 'Why DCF Capital Budgeting is Bad for Business and Why Business Schools Should Stop Teaching it.' Accounting Education: An International Journal, Vol. 15, No. 1: 25-28.

27. Wouters, Marc J. F. 2006. Teaching Capital Budgeting as Multi-attribute Decision-making. A Commentary on 'Why DCF Capital Budgeting is Bad for Business and Why Business Schools Should Stop Teaching it.' Accounting Education: An International Journal, Vol. 15, No. 1: 29-33. 
NOTES 